\title{
LAS PRETENSIONES DE LOS INFANTES \\ DE LA CERDA A LA CORONA DE \\ CASTILLA EN TIEMPOS DE SANCHO IV Y FERNANDO IV. EL APOYO ARAGONÉS
}

\author{
Ángeles Masia de Ros
}

El infante Femando llamado de La Cerda, hijo primogénito de Alfonso X el Sabio, y Violante de Aragón, hermana de Pedro el Grande, y por consiguiente heredero de la Corona de Castilla, murió en Villareal, hoy Ciudad Real, en 1275 cuando se dirigía a la frontera de Andalucía amenazada por los benimerines. En aquellos momentos el rey Sabio estaba en Roma defendiendo sus derechos a la causa del Imperio, por cuyo motivo el infante ostentaba la Regencia del Reino.

El infante Fernando estaba casado con Blanca de Francia, hija de San Luis, de la cual tuvo dos hijos, Alfonso y Fernando. Antes de morir encomendó la defensa de los derechos al trono al magnate castellano don Juan Núñez de Lara, quien cumplió su promesa durante el largo pleito que se desarrolló alrededor de la defensa de los derechos del infante Alfonso a la corona de Castilla.

En virtud del derecho de representación incluido en «las partidas», pero aún no vigente, el infante Alfonso tenía derecho a la corona. A la muerte de Fernando, el infante Sancho, segundo hijo de Alfonso el Sabio, acudió a la frontera haciéndose cargo de la campaña y proclamándose heredero frente a los derechos de su sobrino Alfonso.

Aparte de la fuerza que pudiera representar el derecho tradicional sobre las innovaciones jurídicas, Sancho contaba con el apoyo de las hermandades castellanas, las órdenes militares de Calatrava, Santiago y san Juan, además de gran número de nobles, entre los cuales destacaba Lope Diaz de Haro, señor de Vizcaya. Frente a éste se alzaba otro noble poderoso, Juan Núñez de Lara, quien cumpliendo la promesa hecha a Fernando de La Cerda en su lecho de muerte, se constituyó en defensor de los derechos de sus hijos. 
Aparte de la consideración de si era legal o no la aplicación del derecho de «las Partidas», a la sucesión de Alfonso X, el apoyo que recibió Sancho es muy explicable dado el talante del personaje, inclinado a considerar de primordial interés los asuntos interiores del país. Su actuación a la muerte de su hermano causó muy buena impresión, y a este elemento positivo debemos sumar la impopularidad que «el fecho del Imperio» alcanzó en Castilla. Por estas causas, creemos que fue bien acogido el gesto de Sancho. Inmediatamente, camino de la frontera, se hizo proclamar Rey en Toledo. Todo el mundo aceptó el hecho, menos Juan Núñez de Lara, que prefirió el destierro a la sumisión. Pasó a Francia a ocuparse de la defensa de los derechos de los desposeídos infantes.

Cuando las Cortes del 1276 reconocieron el derecho preferente a la corona del infante Sancho, apoyándose en la noble vigencia de la ley de «las Partidas» que daba la preferencia a los hijos del heredero fallecido sobre los hermanos de éste, la Reina Violante, abuela de los infantes, en compañía de éstos y de su madre Blanca de Francia, pasó a Aragón, donde fueron muy bien recibidos por su Rey, Pedro el Grande. El viaje se llevó a cabo sin conocimiento de Alfonso X y una de las víctimas del disgusto del monarca fue su hermano, el infante Fadrique, yerno del señor de los Cameros, a quien, considerado sospechoso de intervenir en la huída, también dieron muerte.

No nos atrevemos a asegurar si la causa de las veleidades del Rey Sabio en el asunto de la sucesión o por temor a las violencias del carácter de su hijo Sancho, apoyó sus pretensiones hasta el punto que hubiera podido provocar una guerra con Francia.

Este peligro quedo conjurado en una entrevista entre Felipe y Alfonso, celebrada el 30 de diciembre de 1280 . Allí se proyectó la creación de un reino para el infante Alfonso de la Cerda, formado con los territorios del antiguo Reino de Jaén, que debía quedar sujeto a Castilla en calidad de tributario. El infante Sancho, apoyado por Aragón, se negó a aceptar tal solución, y desde este momento las diferencias entre padre e hijo fueron en aumento.

Al manifestarse abiertamente la rebeldía del infante Sancho contra su padre, la Reina Violante regresó a Castilla; sus nietos quedaron en Aragón, pero no ya en calidad de protegidos sino como rehenes, recluidos en el Castillo de Játiva. Su causa, apoyada no en sí misma, sino para dirimir ambiciones y rencores ajenos, comenzó a ser sacrificada a un posible entendimiento entre Pedro el Grande y el infante Sancho. Sancho tenía un gran interés en atraerse a su tío Pedro, ya que consideraba que si éste se mostraba hostil a su causa tenía en sus manos la manera de disputarle el trono: sencillamente libertando a los infantes de la Cerda y reconociendo como rey de Castilla al primogénito Alfonso. 
En aquellos momentos, el Rey Sabio era partidario de la sucesión a favor de Sancho y así lo decidió en las vistas que se celebraron en Campillo y Agreda el 27 y 28 de marzo de 1281 entre Alfonso X, Pedro III y el infante Sancho ${ }^{1}$. En dichas vistas, además de confirmar la sucesión a favor de Sancho, se firmó una alianza, y en un acto de buena voluntad por parte de Castilla, se cedieron a Aragón varias villas fronterizas. También se pusieron de acuerdo para repartirse Navarra. En este asunto el infante Sancho todavía fue más lejos, decidiendo que, cuando fuese rey, la parte de Navarra que le correspondiese del mencionado reparto, sería cedida a Aragón. También se comprometió a la devolución de Albarracín, señorío que anteriormente había sido reconocido como dominio castellano ${ }^{2}$.

A pesar de todo, las relaciones entre padre e hijo siguieron por mal camino, En abril de 1282, en Valladolid, una junta compuesta por prelados y nobles partidarios del infante Sancho, acordó la deposición de Alfonso X. Éste se refugió en Sevilla, donde permaneció hasta su fallecimiento, en abril de 1284. En el mismo año en que fue despojado del trono otorgó testamento a favor de sus nietos, los infantes de la Cerda, y en defecto de éstos la corona de Castilla pasaba a Felipe III de Francia.

La buena relación entre Castilla y Aragón fue de corta duración. Pedro se molestó porque Sancho no acudió a socorrerle cuando Felipe el Atrevido invadió Catalunya. Esta actitud fue doblemente negativa: por faltar al compromiso de una alianza y por no tener en cuenta lo que pudo considerarse como una causa superior hispánica contra un invasor extranjero. Esta circunstancia dio lugar al establecimiento de una alianza franco-castellana que sería una de las constantes de la política internacional de Castilla durante la Edad Media. Si prestamos crédito al cronista Muntaner - quien realmente lo merece-, Pedro, descontento del proceder de Sancho, pensó ir a Játiva, libertar a los infantes y proclamar rey de Castilla al primogénito Alfonso. Este proyecto no pudo llevarlo a cabo, ya que murió en 1285 , un año después que Alfonso el Sabio.

Alfonso el Liberal, sucesor de Pedro, llevó a cabo el proyecto paterno.

Los primeros años del reinado de Alfonso estuvieron ocupados por problemas que le impidieron seguir la política castellana iniciada por su padre. Nos referimos a las luchas con Sicilia, Mallorca, la conquista de Menorca y especialmente la lucha contra los nobles sublevados a los que tuvo que conceder el privilegio de la Unión (1288).

Pacificada la nobleza, pudo Alfonso conceder primacía a los asuntos peninsulares y proseguir la política que su padre iniciara contra Castilla. En consecuencia, en septiembre de 1288 puso en libertad a los infantes de la Cerda, y, en Jaca, Alfonso fue proclamado rey de Castilla. En realidad esta

1 ACA. Rg., 47/103/105, Junta lib. IV, cap. XI-XII.

2 ACA. Rg., 47/100/105, Junta lib. IV, cap. XI-XII. 
medida no era un castigo a lo que juzgaban una traición, ni un interés hacia un cambio de rama dinástica en Castilla, sino la intención de adquirir unas posesiones que ensanchasen sus dominios, a base de anular las consecuencias de los tratados anteriores, que limitaban la expansión aragonesa hacia el sur $^{3}$. Por lo tanto, la ayuda prestada a la causa de de la Cerda era interesada y, en consecuencia, dicho apoyo tenía un precio. Éste fue la cesión del reino de Murcia (1289).

La proclamación de Alfonso de la Cerda tuvo inmediatas consecuencias internacionales; los reyes de Sicilia e Inglaterra le reconocieron en seguida. Muchos nobles castellanos, entre ellos el Señor de Vizcaya, López Díaz de Haro, refugiados en Aragón, se sumaron a ese bando, dispuestos a luchar a favor del nuevo Rey. Este hecho, comparado con la situación aragonesa, víctima del conflicto del Rey con la nobleza, las luchas con la Unión, nos da a entender claramente que en ambos países, y más en Castilla, se encontraba el germen de la guerra civil.

En el trasfondo de todo este problema existía otro muy grave, que era la máxima preocupación de la reina de Castilla, María de Molina. Nos referimos a la legítímización de su boda con Sancho y, como consecuencia, la de los hijos de este matrimonio. Para conseguir tal gracia del pontificado era necesario contar con la amistad francesa; por esta causa, con el tratado de Lión, el 13 de julio de 1288, se llevó a cabo una alianza Castilla-Francia, en la que se acordó conceder al infante Alfonso de la Cerda el reino de Murcia, a cambio, repetimos, de que Felipe IV de Francia, buscase la solución al problema de la legitimidad de la boda Sancho-María; pero el pretendiente a la corona de Castilla no aceptó los acuerdos de Lión, puesto que exigía la totalidad del reino, cosa imposible de obtener, ya que ninguno de los que se presentaban como sus valedores estaba dispuesto a prestar un apoyo desinteresado.

${ }^{3}$ Nos referimos a los tratados de Tudelen, Cazorla y Almizra. El primero en 1151 , entre Alfonso VII y Ramón Berenguer IV. Alfonso, como manifestación de la idea imperial, se irroga al derecho de conquistar toda la España musulmana, y haciendo uso de este derecho concede a Ramón Berenguer las tierras de Valencia, Denia y el reino de Murcia salvo el castillo de Lorca. Ramón Berenguer debe prestar homenaje a Alfonso por estas tierras. M. PIDAL, El Imperio Hispánico y los cinco reinos. El segundo, entre Alfonso II de Aragón y Alfonso VIII de Castilla (1179), concedía a Aragón la reconquista de los actuales límites de las actuales provincias de Castellón, Valencia y la costa de la de Alicante, El tercero en 1344, entre Jaime 1 y el infante Alfonso de Castilla, el futuro Alfonso X. Murcia quedaba excluida de la reconquista aragonesa. El límite valenciano terminaba en la división de los ríos Júcar y Segura. Rooue CesoBAs, División de la conquista de la España nueva entre Aragón y Castilla. Entre Alfonso, infante de Castilla y Jaime I hay conflietos por la posesión de Játiva, Alicante, Enguera y Alcira. Soldevila I. 333.

${ }^{4}$ En 1289 Alfonso de la Cerda cede Murcia a Alfonso el Liberal a cambio de apoyo para recuperar Castilla. 
Como réplica a este acuerdo podemos considerar la proclamación del infante Alfonso de la Cerda como rey de Castilla, llevada a cabo en Jaca en septiembre de 1288.

Una última tentativa de arreglo se buscó en Bayona en 1290. En ella, Blanca, la madre de los Infantes, con un enfoque mucho más realista de la situación, se declaró dispuesta a parlamentar acerca de sus derechos como princesa viuda y de las cantidades que le debía Castilla desde la muerte de su marido. Creemos que tal decisión fue el resultado del poco éxito de las gestiones llevadas a cabo anteriormente para obtener el apoyo francés.

Cuando parecía que las hostilidades de Aragón contra Castilla iban a comenzar a causa del pleito de los infantes de la Cerda, murió el rey de Aragón en 1291.

El sucesor y hermano de Alfonso, Jaime II, rey de Sicilia, queriendo conservar este reino unido a las posesiones peninsulares, se vió obligado a rectificar la política de su hermano. Deseoso de poder dedicar toda su atención a la cuestión siciliana, buscó la paz en la península y por consiguiente la amistad con Castilla. En las vistas que ambos monarcas celebraron en Soria y Monteagudo, se pactó una alianza cuyo fundamento fue la promesa de matrimonio entre el Rey de Aragón y la princesa Isabel de Castilla, niña de 8 años que fue a residir en el reino de su futuro esposo (1 de diciembre de 1291). El único resultado positivo de tal alianza fue la toma de Tarifa, llevada a cabo con la colaboración de la marina catalana en $1292^{5}$.

En 1295, a la muerte de Sancho IV, Jaime II comenzó la política de hostilidad hacia Castilla. Amparándose en la excusa de que Bonifacio VIII no concedía la dispensa necesaria para su enlace con la infanta Isabel, ésta fue devuelta a su madré

Como resultado de tal orientación, el infante Alfonso de la Cerda volvió a entrar en escena apoyado por Jaime II. Naturalmente tal actitud tuvo un precio: renovar la cesión de Murcia ya realizada en la persona del antecesor de Jaime en el trono, su hermano Alfonso. No fue éste el único beneficio que iba a obtener el apoyo aragonés a la causa de la Cerda. El infante Pedro, hermano del Rey, recibiría Cuenca. El infante don Juan, hermano de Sancho IV, el traidor de Tarifa, obtendría los reinos de León, Galicia y Sevilla a base de resucitar un testamento de su padre Alfonso $\mathrm{X}^{\text {? }}$.

5 Zurita.

${ }^{6}$ Los embajadores encargados de notificar a la reina madre de Castilla la ruptura matrimonial entre Jaime e Isabel deben hacer constar que la causa primordial de la ruptura es no haber podido obtener la licencia pontificia necesaria, requisito al que ya se supeditó la boda al concertarse esta.

${ }^{7}$ BENAYIDES, T, I, cap. I. GeRRROIS MARIA DE MOLINA, Cap. VI y VII. ACA Rg., 252/ 126 v. Benavides II doc. XLI Junta libro VI, cap. XX. Benavides II doc. XLII da la notificación del cambio de soberanía a los hombres de Orihuela. 
También otros magnates apoyaron la causa de de la Cerda, pensando obtener ventajas. Don Juan Núnez de Lara, el noble castellano que prometió apoyar a los infantes de la Cerda, tenía algo que reclamar y que pensaba obtener apoyando a los infantes. Nos referimos al pleito sobre Albarracín, señorío del que había sido desposeído y que deseaba recuperar a toda costa. Jaime era muy consciente de la importancia que tenía la permanencia de tan relevante personaje en el bando de la Cerda, pero como también aspiraba a poseer Albarracín, la cesión de esta importante plaza se fijó en términos muy vagos, a largo plazo, quizá pensando que la conducta del pretendiente al señorío quedaría subordinada a las posibilidades de poseerlo y, por lo tanto, regularía su permanencia en las filas aragonesas. También prestaron su ayuda al pretendiente Alfonso, don Diego López de Haro, deseoso de recuperar el señorío de Vizcaya, aparte de muchos otros.

El ambiente caldeado que se percibía en ambos reinos, llevó a la preparación de una campaña. El infante Pedro fue nombrado general de las tropas aragonesas. El 17 de febrero de 1296, antes de comenzar las hostilidades, Jaime II convocó a sus nobles y feudatarios para que el 11 de marzo estuviesen en Ariza para comenzar la campaña. Con la misma fecha se retó a desafio a Castilla, en nombre de Jaime II y de los soberanos de Granada, Francia, Sicilia y Portugal, y del infante Alfonso de la Cerda, a quien se daba el título de rey negándoselo a Fernando IV y a su madre ${ }^{8}$.

El ejército aragonés entró en Castilla por Almazán y Monteagudo. En San Esteban de Gormaz encontraron las tropas del infante don Juan, las de don Juan Núñez de Lara y las de otros nobles castellanos partidarios de la causa de la Cerda.

El proyecto inicial era apoderarse de León y del territorio de este reino para el infante don Juan, quién en dicha ciudad fue proclamado Rey de León, Galicia y Sevilla. En Sahagún tuvo lugar el reconocimiento de Alfonso de la Cerda como soberano de los reinos de Castilla, Toledo, Córdoba y Jaén. La campaña comenzó por el sitio de Mayorga y duró desde primeros de mayo hasta mediados de agosto de 1296. Mientras éste tuvo lugar, las tropas aragonesas recorrieron la tierra de Campos. La campaña fue un fracaso, a causa de una epidemia de peste en el ejército sitiador, siendo una de las víctimas el infante Pedro de Aragón.

Durante la ausencia de la Península de Jaime, a causa del viaje a Roma, donde obtuvo la investidura de Córcega y Cerdeña, las hostilidades cesaron, pero a su regreso comenzaron de nuevo las actuaciones encaminadas a conseguir el máximo número de partidarios que pudiesen ayudar al triunfo de la causa de la Cerda.

${ }^{8}$ Giménez SOLER. Don Juan Manuel, doc. II. Se trata de una carta de Alfonso II, no da la signatura y ha sido imposible su identificación. 
Como consecuencia de las intrigas del infante don Enrique, tío-abuelo y tutor del niño Fernando IV, algunos nobles descontentos se pasaron al bando de la Cerda. El más destacado fue Alfonso de Haro, hijo del señor de los Cameros. La villa de Almazán cayó en poder de Alfonso de la Cerda, donde éste situó su corte, y desde allí se puso en circulación una acuñación de moneda falsa castellana que contribuyó en gran manera al encarecimiento de la vida. En esto tuvo parte Jaime II, pues fue quien proporcionó a Alfonso los maestros monederos'.

Es muy posible que, buscando una mejora a tan crítica situación, don Diego López de Haro propusiese al rey de Aragón una entrevista con objeto de concertar una tregua durante dos o tres meses. Tal propuesta no fue acogida ni abiertamente rechazada. Jaime dijo que no otorgaría dicha tregua sin consentimiento previo del pretendiente. Consideramos que tal medida debía estar orientada a confirmar a los castellanos que Alfonso de la Cerda contaba plenamente con el apoyo aragonés ${ }^{10}$, aumentado éste con la entrada a dicha facción de algunos caballeros castellanos a quienes se encargó la defensa de la frontera desde la villa de Almazán. Éstos hicieron algo más que cambiar de bando, pues ofrecieron al pretendiente dicha villa y la de Deza".

La marcha de los asuntos peninsulares quedó interrumpida de nuevo a causa de dos estancias de Jaime II en Sicilia, la primera desde octubre de 1298 hasta mayo de 1299. Después de una corta estancia en la península emprendió de nuevo viaje. Dicha ausencia duró desde octubre a diciembre del mismo año.

Durante las estancias de Jaime II en Sicilia, tuvieron lugar en Castilla una serie de luchas e intrigas cuyos principales protagonistas fueron don Juan Nûñez de Lara y los infantes don Juan y don Enrique, Las causas de tal estado de cosas fueron las intrigas de los nobles y las ambiciones de los infantes Juan y Enrique, para asegurar su intervención en la tutoría de Fernando IV. Una de las consecuencias de tales querellas fue que Juan Núñez se reconciliase con María de Molina, cosa que supuso una pérdida importante para el bando de los infantes de la Cerda.

Estando así las cosas, el año 1300 se inauguró con la intención manifiesta de Portugal de intervenir en los asuntos castellanos. El rey Dionís, cuya hija Constanza estaba prometida a Fernando IV, se prestó a servir de mediador en las discordias castellano-aragonesas, y también para poner fin a las querellas de los miembros de la familia real castellana, que se disputaban la tutoría del rey. Nada resolvió en la cuestión de las querellas entre Aragón y Castilla. Jaime no estaba dispuesto a renunciar a Murcia y la reina

9 Gabarols Marla de Molina, p. 120. Benavides, T. II L. Rg. 252 fl. 178.

${ }^{10} \mathrm{Rg} .39252 / 183 / 1$.

11 ZURITA, libro V, cap. XXXII. 
María de Molina consideraba que era un precio demasiado caro para la concordia resultante, a pesar de su gran interés en conseguir una solución.

A pesar de que Jaime hacía la guerra en Murcia, la labor de concordia intentada por Portugal seguía, y cada vez se manifestaba más claramente el deseo de Jaime de buscar la intervención de personajes castellanos que estuviesen conformes en participar en busca de una solución al pleito de los infantes de la Cerda, pero sin olvidar que Murcia debía de quedar en manos de Aragón.

Al mismo tiempo Alfonso de la Cerda no estaba ocioso, no dejando que los demás actuasen en su nombre; prueba de ello es el envío de Bernardo de Segalars a las Universidades de Baez y Jaén. Del trato que las autoridades de dichas localidades tuvieron con su enviado, se desprende que estaban

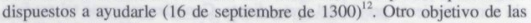
actividades de los hermanos de la Cerda iba dirigido a atraerse el favor de Francia a través de Jaime, según se desprende del agradecimiento que Fernando de la Cerda manifestó desde Paría al Rey de Aragón ${ }^{13}$. Desde luego no podemos demostrar si fueron el consentimiento de Jaime o si éste aceptaba los hechos consumados de la actuación de sus protegidos, que Alfonso tomó iniciativas; especialmente en todo lo que hacía referencia a las relaciones con Granada, es estrecha la colaboración y el intercambio de noticias ${ }^{14}$. Incluso fue informado de la Cerda sobre la concesión de tregua que Castilla solicitó de Granada, concesión que el granadino supeditó al parecer aragonés, cuya opinión fue recomendarle que perseverase en su guerra con Castilla ${ }^{15}$.

En otoño de 1301 se produjo un acontecimiento que debía variar las posturas alrededor de las pretensiones del infante Alfonso de la Cerda. Nos referimos a la bula de legitimización de los hijos de Sancho y María tanto tiempo esperada. La trascendencia de este hecho a nadie se le pudo ocultar y el primero que tuvo conciencia de tal cosa fue el propio pontífice, que buscó una solución al caso de Alfonso de la Cerda. Como artífices de una mediación entre éste y su primo Fernando IV fueron nombrados el obispo de Toledo y el obispo de Sigüenza. A pesar de los buenos oficios de los mencionados prelados, nada se consiguió; Fernando se negó a toda negociación alegando que el pretendiente se había aliado con Granada y además le corría las tierras fronterizas. La mención de la alianza de la Cerda con

${ }^{12}$ Rg. 334 fl. 35 verso/2, 16-IX-1300.

${ }^{13}$ CRD Jaime II, caja 811117 .

${ }^{14}$ CRD Jaime II caja, 10/1322, 3-II-1302. Alfonso de la Cerda acusa recibo de la carta de Jaime dándole noticias de la embajada de Segalar. Cuando termine la cabalgada que está realizando le enviará un caballero con cartas blancas y respuesta a todo.

$15 \mathrm{Rg} .334 / 48$ y $57 / 2$, caja $14 / 1803$, el 7 -VII-1302 se envió a Granada a un emisario encargado de firmar paces. Se trata de renovar los pactos anteriores, al comienzo del reinado de Muhamad III. 
Granada fue algo muy positivo para justificar la actitud de Castilla ante el Papa $^{16}$.

Del estado interior de Castilla, de las cuestiones alrededor de las ambiciones de los nobles y de los infantes don Juan y don Enrique surgen problemas que son la causa de que muchos nobles descontentos se sumaran al bando de la Cerđa, que seguía apoyado por Aragón. El infante don Enrique y Diego López de Haro, en buenas relaciones con Jaime II, deseaban una entrevista con éste, ya que consideraban que los asuntos a tratar eran de tal índole que no se podían confiar ni a cartas ni a mensajeros. Posiblemente, para celebrar en ambiente de paz dicha entrevista, Jaime II y los infantes de la Cerda, otorgaron a Castilla una tregua, cuya duración sería, desde el 21 de abril hasta el 15 de agosto de $1303^{17}$.

La entrevista tuvo lugar en San Esteban de Gormaz en fecha que podemos situar a primeros de mayo de $1303^{18}$. Como enviados de Jaime fueron don Artal de Aragón y Sancho García. De parte castellana acudieron el infante don Enrique y don Diego López de Haro, llegando a la conclusión de que se debía apoyar a la causa de la Cerda, pero dicha decisión debía obtener un consenso más amplio y para cllo se acordó celebrar otra entrevista a la que asistieron como enviados de Jaime II, Artal de Azloz y Sancho Garcés. De parte de los solicitantes acudieron el infante don Enrique y Diego López de Haro. Se tomó el acuerdo de celebrar unas vistas a las que asistiría el rey de Aragón en la villa de Ariza ${ }^{19}$.

Paralelas a dichas gestiones, $\mathbf{y}$ probablemente buscando un arreglo más duradero y quizá para poder velar mejor los intereses de su yerno, son las gestiones llevadas a cabo por Dionís de Portugal, que naturalmente tuvieron lugar con el consentimiento de Jaime II, quien otorgó poderes para mediar en tal asunto a Domingo García de Echauri y a Juan Garcés de Aragón, el 4 de marzo de $1303^{20}$. Lo único positivo que se consiguió fue la firma de una tregua que debía mantenerse desde el primero de junio del año en curso 1303 , hasta el 24 de junio del año siguiente $1304^{21}$.

${ }^{16}$ BeNayides, T, II, doc, CCXIII.

17 RG. 235 fl. 52 Tarazona 2l-IV-1303 además, la tregua se anuncí a Fernando de la Cerda, vicegerente de procurador de Aragón, procuradores de Valencia y Murcia, a todos los reinos y en especial a las ciudades fronterizas de Calatayud, Daroca y Albarracín. También se le notifica a Alabec, jefe de los caballeros marroquíes al servicio de Jaime.

18 ZURTA, libro V, cap. LIV, LVII, LIX. BENAvides I, cap. X. GaJBross Madia dE MoLINA, cap. XIX.

19 Según Zurita, a primeros de abril. Podemos afirmar que fue más tarde, el 10 de mayo, pues el 30 de abril Alfonso de la Cerda ruega a Jaime que acuda a San Esteban de Gormaz en la fecha mencionada, CRD caja 15/1933.

${ }^{20} \mathrm{Rg} .334$ il. 104/105/106 v, 4-III-1303.

$21 \mathrm{Rg} .106$ v/1/2, 108 v 2/3. CRD 15/1927/1940/1943. Alfonso de la Cerda notifica a Jaime II que varios nobles castellanos se pasan a su bando, entre ellos: Juan Manuel, Diego López de Haro y otros que no nombra, 
Mientras ocurrían tales hechos Jaime II procuraba allegarse partidarios que contribuyesen a reforzar el partido de Alfonso de la Cerda, dándole siempre a éste una primacía y subordinando sus propias decisiones al visto bueno del pretendiente ${ }^{22}$.

A mediados de junio de 1303 se celebraron las vistas de Ariza. En ellas tomaron parte Jaime II y los castellanos partidarios de Alfonso de la Cerda. Éstos eran el infante don Enrique, don Diego López de Haro señor de Vizcaya, su hijo don López y don Juan Manuel. El objeto de tal reunión era buscar una concordia entre el pretendiente y su primo, rey de Castilla, que resultase favorable al primero.

Los acuerdos tomados fueron: que Fernando IV le diese a Alfonso el reino de Jaén y además las localidades de Valdecorneja, Pedraza, Almazán y todas las villas que dicho infante poseía en Castilla por «juro de heredad"; y a su hermano, el infante Fernando, se le debía conceder en tierras y heredamientos lo que se acostumbraba a dar a un infante. Las concesiones no terminaron aquí, puesto que también quedaban favorecidos, a costa de Castilla, naturalmente, don Juan Manuel y Jaime II. Al primero se le concedió Alarcón con sus términos, independiente dicha donación de la posterior obtención de Elche. Al rey de Aragón se le otorgaba el reino de Murcia incluida la villa de Requena (15 de junio de 1303$)^{23}$. Con la misma fecha los castellanos que acudieron a las vistas se comprometieron a conseguir que antes del 15 de agosto, del año en curso, firmasen la aceptación de los pactos establecidos la reina María de Molina, los infantes don Felipe y don Pedro, don Juan Alfonso de Haro señor de los Cameros y el infante Alfonso de Portugal ${ }^{24}$. También se comprometieron don Alfonso Pérez de Guzmán y algunos personajes más ${ }^{25}$.

Es muy difícil creer que todos los que le elaboraron el proyecto pensasen que Castilla aceptaría ser despojada de parte de sus dominios y que se avendría a dotar a su rival con la esplendidez que se le pedía, después de

${ }^{22}$ Rg. 344/114/v/3, 9-V-1303. Embajada de Pedro Martínez, que va a ver a Alfonso de parte de Jaime para averiguar si dos hombres buenos que han voluntad de tenerse en aquello que dicho es que los enferme o los envie enformación luego que por razon de questa tregua quel rey d'Aragon no podra dar ni recibir sin voluntad del rey Alfonsos, y que concierie la entrevista de Jaime y Juan Manuel y el proyecto de boda de éste con la infanta Constanza de Aragón. Éste llevara como arras Elche, cuando dentro de ocho años pueda realizarse el matrimonio e suma dicho matrimonio. Participa que la vista se celebró en Ariza a mediados de junio. Id. Artal de Azlor y Sancho Garcia de Loriz y el 15 del mismo mes, al infante don Enrique y el señor de Vizcaya, Diego López de Haro.

${ }^{23} \mathrm{Rg} .292 \mathrm{fl}, 22$ pergamino Jaime II 1891. BENAvIDES II CCXXXIV. ZURITA, Libro V LIX, 15-VI-1301.

${ }^{24} \mathrm{El}$ infante Alfonso de Portugal, hermano bastardo del rey Dionís, estaba casado con Violante Manucl y tenía posesiones en Murcia.

${ }^{25} \mathrm{Rg} .292$ fl. 23. 
sacrificar Murcia a favor de Aragón. Todo quedó en proyecto y el pleito de Ia Cerda sin solucionar.

En el reparto que comentamos, el infante Alfonso fue el menos favorecido; en realidad no podía ocurrir de otro modo, ya que sus valedores atendieron primordialmente a sus problemas procurando que no quedasen nunca en segundo término. Así lo debió considerar el infante por muy iluso que fuese y en consecuencia buscó una solución distinta. Pretendió entrar en Castilla en son de guerra, naturalmente ayudado por Jaime. Éste procuró dar largas al asunto aduciendo que sería prematuro y quizá contraproducente una ruptura de hostilidades antes de haber recibido respuesta de la reina María y de su hijo Fernando. Además, para reforzar estos argumentos, le recordó que había treguas en vigor ${ }^{26}$.

En realidad, la guerra con Castilla a favor de los derechos al trono de Alfonso de la Cerda no convenía a nadie, ya que, en ella, todos, salvo el pretendiente, tenían más cosas positivas que perder que problemáticas por ganar. Nos referimos a las cuestiones que tenían pendientes los señores castellanos que apoyaron la causa de la Cerda, el señor de Vizcaya y don Juan Manuel especialmente, de forma que la defensa de tales intereses presagiaba acuerdos más o menos duraderos, solución que se consideró preferible a una actitud violenta.

Para la afirmación que acabamos de apuntar nos apoyamos en el hecho de que la reina María de Molina inició negociaciones con Jaime II. El 9 de octubre de 1303, éste le comunica que no piensa hacerle la guerra, y el 15 del mismo mes acusó recibo de la visita del obispo de Osma, procurando que todo discurriese por vías de paz ${ }^{27}$.

Una noticia favorable es que Jaime volvió a buscar un arreglo con la mediación de Dionís de Portugal, el cual consistía en una reducción de las condiciones exigidas en las vistas de Ariza. A esta conclusión llegamos a través de cartas y embajadas casi todas ellas sólo vislumbradas a través de esporádica documentación, y que además es muy poco explícita, ya que los emisarios de ambas partes no llevaban casi nunca instrucciones escritas. De todo ello se desprende que Portugal envió emisarios a Aragón con el encargo de concertar paz en las discordias y guerras que estaban en curso, «Puynando en baxar de su entendimiento al rey D. Alfonso, seynaladamente en aquella visita que fue en Ariza».

A esto Jaime contestó que «Flexo lo que podio» pero en realidad no consiguió nada. Y es posible que tampoco Fernando consintiese. El parecer de Jaime es que todos los hechos debían de pasar de nuevo a un arbitraje que debía llevarse a cabo con las siguientes bases: que Dionís u otra persona solvente decidiesen lo que los infantes de la Cerda debían poseer

${ }^{26} \mathrm{Rg} .335$ fl. $301 / \mathrm{v}, 28-\mathrm{II}-1304$.

27 Rg. 334, fl. 120-122. 
en Castilla, y, una vez admitida la solución resultante de tal arbitraje debían renunciar a toda reclamación posterior. En cuanto a la cuestión de Murcia, que Jaime decía poseer con pleno derecho, debía de ser puesta en manos de Dionís y dos personajes más: uno representando a Castilla y otro a Aragón, con la promesa consiguiente de aceptar la decisión pronunciada por tales personajes $^{28}$.

La ausencia del infante don Alfonso de la Cerda en todas estas negociaciones que tan directamente le atañían y que oficialmente se llevaban a cabo pensando en solucionar su problema, nos ayudará una vez más a convencernos de que su causa, tomada como bandera para dirimir rencores y ambiciones ajenos, dejaba de interesar. Pero lo cierto es que el infante estaba en Aragón, y actuaba según su parecer, posiblemente confiando en que las soluciones emanadas de los pactos de Ariza se llevarian a término y le convertirían en rey de Jaén. A pesar de que la actitud castellana respecto a los pactos de Ariza era de sobra conocida, el iluso Alfonso creyó que cuando el obispo de Osma fue a ver a Jaime Il de parte de la reina de Castilla, iba a rendirle pleitesía y a pedirle treguas para el cese de las hostilidades en las fronteras de Molina ${ }^{20}$.

El abandono de la causa de la Cerda por parte de todos, especialmente de Jaime II, se nos manifiesta de manera clara. Alfonso envió embajadas que no fueron atendidas, no fue ayudado en sus apuros guerreros. Almazán estaba cercado y no llegaron las tropas de refuerzo que reclamaba, y Morón se perdió por falta de defensores. Jaime, con su habitual proceder ambiguo, contestó a la angustiosa petición de auxilio que comentamos, que no podía socorrerle, ya que necesitaba sus tropas para poder defender la frontera, y considerando todas estas circunstancias, no es extraño que los infantes de la Cerda, especialmente Fernando, desconfiasen del apoyo aragonés y buscasen soluciones negociando directamente con Castilla, cosa que Jaime trató de impedir. Incluso sabemos que reclamó a Fernando el cumplimiento de lo prometido. Nada debió conseguir, puesto que trató de resolver la mala situación económica de los hermanos concediendo a Alfonso 10.000 maravedises a cargo de la judería de Zaragoza ${ }^{30}$.

A pesar de todos los optimismos, al fin, el infante Alfonso debió también de considerar perdida su causa, ya que aceptó someterse al arbitraje que sobre sus diferencias con Fernando de Castilla pronunciasen los reyes de Aragón y Portugal. Jaime, como representante suyo, recibió poderes para firmar tregua con Castilla durante un año, o por el tiempo que se considerase conveniente (10 de enero de 1304). El 20 de febrero, el infante don Juan los recibió de su sobrino y pupilo, el rey de Castilla, con objeto de

${ }^{28}$ CRD caja 15/1946, caja 16/2004.

${ }^{29}$ CRD caja 15/1921. ZURITA, libro V. cap. LXIII dice que Jaime envió socorros para cercar Morón. Rg. 335 fl. 309/vta.

${ }^{30}$ BENAVIDES I CCLI, CCLII Y CCLV, 10-I-1304. CRD caja 18/2336. 
ajustar paces en todo lo que hiciese referencia a los infantes de la Cerda ${ }^{31}$. Es natural que el incumplimiento de los pactos de Ariza tuviera alarmados a los infantes, especialmente a Fernando, más pesimista y tal vez más clarividente que su hermano. A su propuesta de aceptar «un adobo» con Castilla, Jaime trata de evitarlo y le propone que vaya a reunirse con él, seguramente con objeto de convencerle ${ }^{32}$.

Entre las dos fechas que acabamos de citar, el 10 de enero y el 20 de febrero, tienen lugar las diversas actividades de los infantes de la Cerda, especialmente de Fernando, más realista y activo que su hermano, buscando como hemos dicho una solución prescindiendo de Jaime II. Suponemos que los infantes estaban al corriente de los contactos que mantenían el rey de Aragón y el infante don Juan con anterioridad a los nombramientos de procurador por parte de ambos, y también de las ingerencias del rey de Portugal, que no debemos olvidar que era suegro de Fernando IV. Muy alarmado debía estar el infante Fernando acerca de las intenciones del infante don Juan respecto a ellos. Suponemos que debió confiar sus recelos a Jaime II, cuando éste le escribió tranquilizándole, diciéndole que no prestaría oídos a nada que contra él y su hermano Alfonso dijera el dicho infante don Juan ${ }^{33}$.

Las negociaciones que acabamos de comentar dieron como resultado la promulgación de una nueva tregua. Según Jaime, notifica a Alfonso de la Cerda el 9 de marzo de 1304, ésta debía durar hasta el primero de mayo. Dicha tregua no fue respetada, especialmente por los caballeros granadinos al servicio de Aragón cuyo jefe era Alabez Abenraho. Tampoco la respetó el infante de la Cerda ${ }^{34}$, que se mostraba receloso del comportamiento del infante don Juan. Aunque en concreto no sepamos a qué pueden referirse tales aprensiones sí podemos afirmar que entre el infante y el rey de Aragón existían relaciones epistolares, pero no que llegasen a entrevistarse en Calatayud en fecha anterior a la promulgación a la tregua. Es posible y natural que tales actividades fuesen conocidas de los hermanos de la Cerda y que los tuvieran inquietos, y mucho más si se enteraron de que los resultados de dicha entrevista fueron comunicados al rey de Portugal por Jaime $\mathrm{II}^{35}$.

${ }^{31}$ Rg. 235 fl. 9/2, 9/v/2-10/1, caja 2218 Juan Manuel 90.

${ }^{32} \mathrm{Rg} .235$ fl. 9/2/10/1 CRD, caja 17/2218 Juan Manuel doc. 90 . Rg. 235 fl. 20/vto/2 CRD, caja $18 / 2336 /$ c. $17 / 2231 / 2241 . R g .152161 / \mathrm{v} / 4$.

${ }^{33}$ CRD, caja $17 / 2225$.

${ }^{34} \mathrm{Rg} .339 \mathrm{fl}$. 123/vto, 13-III-1304, *Post vistas habitas inter dominum regem et infantem Johanem in Calatayuds. Gonzalo Pérez, comendador de Santarem, preenviado a Portugal a contar la entrevista a Dionís. $\mathrm{Rg} .235 \mathrm{fl} / 38$ y 38/2, 9-III-1304, se ratifica la tregua a los infantes de la Cerda. Fernando IV la publica en Burgos el 15 IV. CRD, caja 26/3331/1.

35 ZuRrTA, libro V, cap. XVI. 
Consecuencia de la entrevista fue que para la solución de las diferencias que sobre la posesión del reino de Murcia y la dotación de los infantes de la Cerda tenían Aragón y Castilla, se tomó la decisión de que los litigantes se sometieran al juicio que sobre ambos casos pronunciasen determinados personajes. Para preparar tal arbitraje se acordó una entrevista entre los reyes de Aragón, Castilla y Portugal. Dicha reunión tuvo lugar en las llamadas vistas del Campillo, lugar situado entre las poblaciones fronterizas de Ágreda y Tarazona. Reunidos en dicha villa el 20 de abril de 1304, los reyes de Castilla y Aragón y el infante Alfonso de la Cerda, acordaron aceptar como árbitros de sus querellas al infante don Juan, a Jaime II, el rey Dionís de Portugal y al arzobispo de Zaragoza, Jimeno de Luna. Como garantía de aceptación de lo acordado, se entregaron castillos de rehenes. Dicha entrega se llevó a cabo con todas las formalidades de rigor en estos $\operatorname{casos}^{36}$. También los nobles en discordia se otorgaron una tregua que se publicó el 30 de abril y parece ser que se procuró que fuese mantenida ${ }^{37}$. A partir de este momento y hasta la celebración de las vistas son muy numerosos los intercambios de noticias y embajadas entre los reyes de Aragón y Portugal, directamente y por mediación del infante don Juan ${ }^{38}$. Éste, desde Viseo el 10 de junio de 1304, comunicó a Jaime el envío del sacristán de Tarazona, Diego García Echauri, y del Arcediano de la guardia, Ramón de Monros. En las cartas de que eran portadores le recomendaba: «Non entredes en Castilla por esta tierra de aca, cuando podiesseres porque el rey de Portogal se pueda veer con vos lo más ayna que pueda ser.» En efecto el rey Dionís salió de Sabugal el 25 de junio calculando llegar a San Esteban de Gormaz a los 15 días. A estas vistas, preparación de las del Campillo, fue convocado también Alfonso Cerda ${ }^{39}$.

Paralelamente a estas gestiones, que podemos calificar de protocolarias, tienen lugar otras más interesantes, puesto que se proponen sondear el ánimo de personajes cuyo parecer interesaba conocer a las partes en discordia. Aragón y Castilla enviaron emisarios a Portugal, naturalmente por separado, dándose la imprevista circunstancia de que ambas embajadas coincidieron $^{40}$.

De las noticias que de tales embajadores a la reina Isabel a su hermano nada podemos decir, puesto que su contenido está confiado verbaimente a

${ }^{36} \mathrm{Rg}$. 1521 fl. 6 Tarazona, 20-IV-1304, se nombran los árbitros. Los castillos fueron por Aragón, Verdejo, Somel, Borja, Malón, y Ariza; por Aragón, Alfaro, Cervera, Aetón, San Esteban y Aticnza.

${ }^{37}$ CRD, caja 95/11555, Santarem 18-V-1304.

${ }^{38}$ CRD, caja 148/423, Coimbra 1.VI-1304. La noticia de la paz le viene a Dionís de los enviados Domingo García y Ramón de Monros.

39 CRD, caja $148 / 2256 / 2263$. Rg. $235 / 90 / 2$ lista de personas que vienen a las vistas.

${ }^{40}$ CRD, caja 148/2248/2236. 
los enviados, Martín Pérez de Fontova y Gonzalo García ${ }^{41}$. Durante la segunda quincena del mes de julio tuvieron lugar los desplazamientos hacia el lugar de las vistas de todos sus componentes. Veamos con que ánimo acudían.

Los autores que hasta el momento se han ocupado de esta cuestión, especialmente Zurita, y la Crónica de Fernando IV, de Benavides, dan relación más o menos detallada del transcurso de la reunión y de la resolución que en ella se adopta, pero no se detienen en el examen del ánimo que a tal reunión llevaban los interesados en el asunto a debatir. Nos referimos a las intenciones de Castilla y Aragón, de cuyos dominios debería segregarse todo lo que se concediera a los infantes de la Cerda.

Los tratos de Jaime II cerca de Francia, nos permiten suponer el propósito con que el rey aragonés acudía a las vistas. En carta fechada en Zaragoza el 21 de julio, o sea en su plena preparación, nos permite deducir que la intención de Jaime será procurar que Castilla le ceda a Alfonso lugares *con mero y mixto imperio» a cambio de renunciar a llamarse rey. La consecuencia de tales condiciones sería el reconocimiento de Fernando IV como soberano de Castilla y el final del pleito ${ }^{42}$.

\section{SENTENCIAARBITRAL}

Las decisiones emanadas de los reunidos en el Campillo (8-VII-1304) alcanzaron a varias cuestiones, dominando el propósito de solucionar las ambiciones de varios personajes, destacando entre ellos, Jaime II y el infante Alfonso.

El primero alcanzó gran parte de lo que pretendía. Se le adjudicaron todos los lugares situados a la izquierda del Segura hasta su desembocadura, salvo las localidades de Melina-Seca y Murcia. Enclavadas en estos límites quedaban posesiones pertenecientes a don Juan Manuel y a su hermana Violante. Éstos conservaban sus propiedades aunque bajo la jurisdiccion aragonesa.

La parte más complicada de los problemas que habían dado lugar a la reunión que glosamos, los derechos del infante Alfonso, quedaron relegados a segundo término. Se le buscó solución de acuerdo con la opinión sustentada por el rey de Aragón cerca del rey de Francia, más sin que mi siquiera pudiese plantearse la cuestión de reconocerle como rey ${ }^{43}$.

${ }^{41} \mathrm{Rg} .235$ fl. 93/vto/2 y $112 / 3$. En esta última carta dice saber por Ramón de Monrós que el rey Dionis se prepara para asistir a las vistas,

${ }^{42} \mathrm{Rg} .1521 \mathrm{fl} .43 / v / 2$. La carta está fechada en Zaragoza el 21 de julio, o sea en plena preparación de las vistas.

${ }^{43} \mathrm{Rg}, 1521$ fls. 9-21, contiene toda la marcha del arbitraje y la sentencia resultante. BeNavides IICCLXXX, esta última es Melina-Seca. 
De acuerdo con esta solución, lo que se adjudicó al infante Alfonso fue sencillamente lo que le correspondía como infante de Castilla, otorgándole las villas de Almazán, Serón, Deza y Alcázat ${ }^{44}$. Los lugares concedidos debían producir una renta anual de 400.000 maravedises y, de no ser así, se aumentarían las donaciones hasta alcanzar dicha cantidad ${ }^{45}$.

La solución dada al pleito de la Cerda, ni de salomónica puede calificarse, pero si tenemos en cuenta quienes arbitraron en el asunto y pronunciaron la sentencia resultante, no podía ocurrir de otro modo. Hay que considerar que entre los que intervinieron más directamente y tenían más intereses que defender se encontraban Jaime II y Dionís. El primero salió ganando, y también nos permitimos suponer que Dionís se conformó con que Castilla fuera la única que cedía territorios a cambio de considerar terminado el pleito.

Examinando la situación geográfica de dichos dominios veremos que se tuvo mucho cuidado en evitar que formasen un todo compacto, estando repartidos por toda Castilla, Galicia y Andalucía, y lejos de las fronteras de Aragón. Probablemente, por dicha causa Alfonso se vió obligado a devolver Serón, Deza, Alcázar y Almazán. Y para solventar el peligro que podía suponer que Alfonso alimentara veleidades regias, se le obligó a no usar armas de castillos y leones acuartelados como los reales sino diferenciados. También fue objeto de consulta deslindar si Alfonso debía recibir pleito homenaje de los habitantes de las posesiones concedidas ${ }^{46}$.

La actualización de todos los extremos contenidos en la sentencia que comentamos, menciona en último lugar al infante Alfonso de la Cerda, causante oficial de todo. La vigencia de las conclusiones, en especial la cesión de Murcia a Aragón. quedó condicionada a que el infante Alfonso aprobase y aceptase la solución que ya conocemos. Tal aprobación tuvo lugar el 16 de agosto ${ }^{47}$.

$\mathrm{Al}$ infante Alfonso no le quedaba otra alternativa, ya que le suponemos enterado de que el 9 de agosto, al día siguiente de la aprobación de la sentencia arbitral, los reyes de Aragón, Castilla y Portugal, junto con el infante don Juan, firmaron una alianza ${ }^{48}$. Asimismo, los reyes Fernando y Jaime pactaron por separado, prometiéndose mutuamente no dar acogida a nobles o caballeros en rebeldía contra sus soberanos ${ }^{49}$.

El cumplimiento de la sentencia era la solución a los problemas que ella teóricamente solventaba, pero su aceptación no demuestra su cumplimien-

${ }^{44} \mathrm{Rg}, 1521$ fl. 29/vto/2. Benavides CCL XXXIV. BENAVIDES I p. 135. ZuRTtA, libro V, cap. XVI.

${ }^{45} \mathrm{Rg} .1521 \mathrm{fl} .197$ vto.

45 Benavides 1, p. 165 y II doc. CCL XXXIV y Rg. 1521 fl. 42 vto.

47 CRD, caja $17 / 2259$.

48 CRD, caja $263332 / 12$.

49 RG $1521 / 24 / v$, BENAVIDES II CCL.XXXVI. 
to. Debemos recordar que en dicha solución, Castilla era la única perdedora, puesto que a su costa se daba cumplimiento a las ambiciones del rey Jaime Il y se dotaba al infante Alfonso de la Cerda. A pesar de lo que esto suponía para Castilla, considerando la cuantía de las donaciones, la reina María lo acept 6 , ya que de esta forma quedaban zanjadas dos preocupaciones: la guerra con Aragón y el pleito de los infantes de la Cerda.

Una posible reanudación de actividades de dichos personajes debía descartarse por varias causas. Jaime, aunque no consiguió cuanto deseaba, o sea la totalidad del reino de Murcia, conservó lo que le fue concedido por quien no lo posé́a y consiguió que su protegido y aliado fuese dotado por quien había pretendido despojar. Además, debemos tener en cuenta la impopularidad de la causa de la Cerda en Castilla y el abandono en que Felipe el Hermoso tuvo a sus parientes ${ }^{50}$.

Además de lo expuesto sobre el ánimo de los interesados, la escasa documentación referente a esta cuestión nos permite deducir el poco interés de Castilla por cumplir sus obligaciones. Durante todo el mes de agosto, plazo en que todo debía quedar resuelto, Fernando y Jaime trataron de que todo lo proyectado se llevase a cabo, pero en realidad nada definitivo se produjo. Muy desanimado debía estar Alfonso cuando decidió ir a Francia a entrevistarse con su pariente el rey. Para ello le pidió a Jaime el socorro y las cartas prometidas ${ }^{5}$. El viaje se llevó a cabo, pero nađa resolvió, puesto que desde San Marcel, localidad cercana a París, donde vivía Blanca, la viuda de Fernando de la Cerda, Alfonso rogó a Jaime que intercediese cerca de Fernando para que éste cumpliese los compromisos adquiridos ${ }^{52}$.

Cuando el infante regresó de Francia, desde Deza se preocupó de averiguar qué se pretendia con un «alongamiento» del plazo dado para dar y recibir del rey de Castilla lo convenido entre éste y el de Aragón ${ }^{53}$. Desconocemos las gestiones por las que Fernando estaba dispuesto a la entrega de Béjar, Valdecorneja, Manzanares y los montes de Greda. El infante don Juan fue nombrado procurador de su sobrino Fernando IV en sus querellas con Alfonso. Los lugares asignados a Alfonso no fueron de su agrado, $y$ hubo discrepancias entre los dos primos acerca de un posible cambio. Fernando propuso el trueque de Pedraza por los molinos de Atienza, que rentaba 80.000 maravedises, trueque que Alfonso no aceptó porque prefería Cangas, Trujillo o Cáceres. El infante don Juan, contrariado por las veleidades de su protegido, intentó la intervención del rey de Aragón procurando que Alfonso aceptara las sugerencias de Fernando, máxime teniendo en cuenta que según dice se le entregaron ya Valdecorneja, Alba de Tormes y el Real de Manzana-

\footnotetext{
So MARIA DE MOLINA, cap. XXI. ZURITA, libro V, cap. LXVI.

SI CRD, caja $17 / 2245,25-$ VIII-1304.

52 CRD, caja 23/2927, 30-DX-1304.

53 Caja 17/2264.
} 
res $^{54}$. No conocemos la actuación de Jaime en este asunto, pero sabemos que siempre procuró que su oficialmente protegido aceptase, como hizo desde un principio, las conclusiones de la sentencia arbitral de la que Jaime era uno de los autores.

No debemos olvidar que el pleito de los infantes de la Cerda no era el único que esperaba solución, y por lo tanto, todo, especialmente dicho caso, estaba supeditado al vaivén de los acontecimientos y de los intereses de otros personajes, todos ellos con una fuerza propia que les permitía imponerse. Nos referimos al infante don Juan, a don Juan Manuel, y a las querellas alrededor de la posesión del señorío de Albarracín, codiciado por el rey de Aragón y don Juan Núñez de Lara. Aparte de este asunto, Jaime tenía también intereses que defender. Tales eran sus pretensiones al reino de Murcia del que se créa legítimo poseedor, aunque se diese la circunstancia de que quien se lo dio no lo poseía.

Estas cuestiones dieron lugar a que se convocasen unas nuevas vistas, las que se celebraron en el monasterio de Santa María de Huerta, en los alrededores de Soria, el 26 de febrero de 1306. En ellas, se atendió principalmente a las diversas cuestiones que se derivaban de los acuerdos sobre Murcia: los límites de la parte cedida a Jaime y las posesiones en dicho reino de don Juan Manuel y su hermana Violante, esposa de Alfonso de Portugal $^{55}$. En cambio, en tal reunión no se mencionó el asunto del infante Alfonso.

Algo debía esperar éste de las resoluciones emanadas de la reunión del monasterio de Huerta, ya que no fue casual que el 27 de febrero, el día siguiente del comienzo de tales vistas, Jaime le rogara a Dionís una intervención cerca de su yerno para conseguir de éste el cumplimiento de lo prometido $^{56}$. Pero en realidad, durante este tiempo el infante actuó como soberano, admitiendo la tregua que Jaime firmó con Castilla desde marzo al primero de mayo, y publicándola en Deza y Serón. Si estas localidades debían ser devueltas al recibir lo estipulado y seguían en sus manos, demuestra que no recibió lo prometido ${ }^{57}$.

Otra fuente de discordia fue la posesión, por parte de Alfonso, de la villa de Monforte en tierra de Lemos, posesión que le discute el infante don Juan, lo mismo que el obispo de Ávila pretende ser el poseedor de Valdecorneja.

Jaime procura que no le demoren dichas entregas, ya que Alfonso debía poseerlas con los derechos que en ellas siempre tuvieron los reyes y que le pusieran sobre otra heredad los derechos de 60 mil maravedises que debían devengar las salinas de Atienza. Asimismo se debía procurar que los judíos

54 CRD, caja 105/13117, caja 26/3332/9, caja 17/2217, 22-X-1304.

55 BenAvides II CCCXXIV, CCCXXV doc., de la colección Salazar A 2 fls. 178, 179 v.

${ }^{56} \mathrm{Rg} .1521$ fl. 59/vto., 27-II-1305.

57 RCD, caja 17, 12-VI-1305. 
residentes en las localidades asignadas pagasen lo establecido. Dichas gestiones fueron encomendadas al escribano de Jaime, Pedro Martínez ${ }^{58}$.

Mucha debió ser la desconfianza de Alfonso acerca de las gestiones que acabamos de mencionar, puesto que intentó de nuevo obrar por su cuenta. Desde Teruel se comunicó a Jaime que a raíz de un viaje de un escudero de Alfonso a Murcia, se susurraba que Murcia y Lorca, con ayuda de Granada, se alzarían en favor de la causa de de la Cerda. La respuesta del rey de Aragón fue contundente: que el infante afuese puesto a buen recaudo" ${ }^{5}$. En qué medidas se materializó la orden de Jaime lo ignoramos, pero los acontecimientos posteriores nos permiten suponer que se incrementó la vigilancia, puesto que las gestiones encaminadas a obtener el cumplimiento de los compromisos contraidos seguían adelante.

Al fin Fernando aceptó entregar al infante Alfonso los 400 mil maravedises para que le fueran entregadas Deza, Serón y otros lugares a tenor de la sentencia de Torrijos ${ }^{60}$.

No estaría muy bien dispuesto Fernando a cumplir los compromisos contraídos cuando en el mes de octubre se envió a Castilla a un embajador, Guillem Palazín, con autorización para recibir lo que debía entregarse al infante. Y algo temería Jaime respecto a la liberalidad de Fernando, ya que aconsejo a Alfonso «que por poca cosa non querades contender con el rey ${ }^{61}$. De tal embajada nada se obtuvo. Según el infante Juan todo estaba supeditado al apoyo que Jaime podía prestar a Fernando en su lucha contra don Juan Núñez y el Señor de Vizcaya ${ }^{62}$. En junio, se insiste sobre lo mismo en una embajada confiada a Juan del Gay, en la cual se especificaban detalladamente las reclamaciones presentadas. De su examen se desprende que las rentas que tales donaciones producían no alcanzaban la cantidad estipulada, los tan mencionados 400 mil maravedises. Según Jaime se trata de compensar con 20 mil maravedises la mitad de la atunería que se le concedió, y además consideró que el infante de la Cerda debía poseer libremente Tordehumos, Torreblanca y los demás lugares que le fueron asignados "francos e quitos de senyorio " ${ }^{63}$.

No obstante, la solución no llegaba. El 14 de julio el infante don Juan dio noticias vagas sobre la solución que proponía Juan del Gay ${ }^{64}$. Una

38 fd., $94 / 11528,19 / 24818$ y $1521 / 66 / 2$.

59 fd., 117876 recto y verso la contestación a la noticia se da con sólo cinco días de intervalo y la minuta está redactada al dorso de la primera, 21 y 26-V-1305.

60 CRD, caja 20/2545, Huerta de Ariza, 26-II-1306.

$61 \mathrm{Rg} .236 / 103$ vto, y 109 vto.

62 CRD, caja 21, 2662, 25-IV-1306.

$63 \mathrm{Rg} .23$ 6/181. Estas cartas pertenecen al 1-VI-1306. Diego García, conceller de Castilla afecto a la causa de Jaime, recibe el encargo de procurador que el rey Fernando acepta las soluciones que proponga Juan del Gay.

64 CRD, caja 21/2744. 
nueva complicación fue que apareciese de nuevo el problema de Monforte. Diego García, canciller de Castilla, escribió a Jaime sobre este tema y en contestación a la misiva, que desconocemos, Juan del Gay es de nuevo enviado a Castilla con la misión de decirle al canciller que aconsejase a Fernando que se mostrase favorable en los asuntos referentes a Alfonso de la Cerda ${ }^{65}$. El objetivo príncipal del viaje de Juan del Gay fue tratar del cambio que obtendría Alfonso de la mitad de la atunería que se le concedió por 10 mil maravedises ${ }^{\circ 6}$. Otra de las reclamaciones encargadas al emisario aragonés fue la entrega de Torreblanca y Siete Colinas, "francos e quitos». También se quejó el infante Alfonso de que no recibía las rentas que devengaban dichos lugares. Esta reclamación, dirigida personalmente al rey de Castilla, se repitió al infante don Juan y al Canciller Diego García ${ }^{67}$. Nada se. consigue; las negociaciones son largas y prolijas a juzgar por el largo período en que se llevan a cabo, entre el 6 de mayo y la misma fecha de noviembre de 1307.

El caso de Monforte se presentaba más complicado, ya que estaba en litigio la forma en que el rey de Castilla ostentaba la propiedad de dicha población. Al desconocerse esta circunstancia cuando se redactó la sentencia, Jaime fue partidario de aplazar la solución de dicho pleito hasta que se llevasen a cabo las vistas proyectadas ${ }^{68}$. La demora de las negociaciones y su nulo resultado fueron seguramente la causa de que el infante Alfonso fuese de nuevo a Francia en busca del apoyo que tantas veces se le había negado. Ignoramos qué debió contar a Jaime Juan de Rocaforte, cuya visita anunció Alfonso desde Poitiers ${ }^{\circ \%}$. A dicha estancia en Francia creemos que puede pertenecer la carta que sin fecha de año, un 20 de junio, escribe el infante a Jaime, diciendo «que avemos ajora muy bien adobado nuestros esguardos con el rey de Francias ${ }^{70}$. Nos inclinamos a creer que «nuestros esguardos» deben referirse a relaciones personales, no a la intervención francesa en las reclamaciones de Alfonso.

Durante la permanencia en Francia del pretendiente, algo se solucionó como resultado de la embajada de Juan del Gay, ya mencionada. Dicho embajador reconoció haber recibido del rey de Castilla una serie de lugares, cuyas rentas debían formar parte de la cantidad estipulada de 400 mil maravedises. Lo curioso es que los lugares que recibe Juan del Gay no son los mencionados en la sentencia arbitral de Campillo. Se habla de «Gibraleón, Garganta la Olla, Torre Menga y Pasarón, en el término de Algeciras; Aldea Mayor, con las salinas del Compás, las

$65 \mathrm{Rg} .236 \mathrm{fl} .181 \mathrm{vto} / 1$.

$66 \mathrm{Rg}, 236 \mathrm{fl} .181$ vto $/ 1$. Ey non quissieremos que desta meetat quel devedes agora en cento de 20 mil maravedises menoscabase tanto ni ende fesse dampnificado o que sobre esto vos embiassemos regar.

$67 \mathrm{Rg} .236 / 182$.

${ }^{68} \mathrm{Rg} .236 / 224,25-\mathrm{VIII}-1306$. CRD $22 / 28020(\mathrm{~b} / \mathrm{c}), 7-\mathrm{XI}-1306$.

$\oplus$ CRD, Caja 23/2954, 7-IX-1307.

70 CRD, caja 159/1923, 20-VI-1307. 
salinas de Ru, las aceñas de Córdoba, Collera, la mitad de las torres de Haznalcazar, la mitad de Torreblanca (cerca de Ynoios) en el alxarafe de Sevillas ${ }^{71}$.

Al día siguiente, Juan del Gay reconoció haber recibido de Martín Ruiz de Foces, procurador y canciller de Alfonso de la Cerda, un albarán del pago de 2.000 maravedises que hizo el rey de Castilla a cambio de la entrega de Collera y las demás localidades que se mencionan en la carta de recepción de dichos lugares ${ }^{72}$.

No sabemos cuándo Alfonso fue de nuevo a Poitiers, desde donde el 6 de noviembre de 1307 comunicó a Jaime que supo por Juan del Gay que la entrega que le hizo el rey de Castilla no alcanzaba la cantidad convenida, en vista de lo cual estaba dispuesto a reclamar Deza, Serón y Alcázar, que, según la sentencia ya mencionada, debía devolver a Castilla. Por lo visto Jaime, jugando con dos barajas como de costumbre, le aconsejó que no reclamase, insinuación que de la Cerda no siguió, sino que le contestó al aragonés que se arrepentía de haber entregado Almazán, pues de no haberlo hecho le hubiesen cumplido los compromisos ${ }^{73}$.

De nuevo en Poitiers nombró a Juan del Gay como procurador para recibir en su nombre la honor de Sarria a cuenta de 30 mil maravedises ${ }^{74}$. Esta gestión debía formar parte de una serie encaminada a buscar una solución definitiva. Pero seguramente hubo alguna discrepancia acerca del cumplimiento de la sentencia en los términos aceptados, ya que de no ser así no se explica que Fernando y su madre tratasen con Jaime para estipular lo que se debía dar al infante Alfonso ${ }^{75}$. Sorprende que el anunciante de tal extremo fuese el infante don Juan.

En qué clima se desarrollaron las entregas mencionadas y cómo fueron acogidas por los afectados lo ignoramos, pero hay que tener presente que la causa de de la Cerda nunca tuvo popularidad en Castilla, y recordar lo forzado de las donaciones, por parte de Fernando. Por esto no es de extrañar que las posesiones que debían pasar al fracasado pretendiente fuesen víctimas de atropellos, lo mismo las enclavadas en Castilla que las pertenecientes a Galicia ${ }^{76}$.

71 CRD, caja 23/2955, 8-IX-1307.

72 CRD, caja 23/2953/2955.

${ }^{73}$ CRD, caja 23/2982, 6-XI-1307.

${ }^{74} \mathrm{CRD}$, caja $20 / 2545,25-$ III- 1308

75 CRD, caja 27/3469 León, 15-IV, 3475 y 3476 17-IV. Valencia, 19-IV-1308. CRD, caja 27/3582. Poitiers, 8-VII-1308, Lope Sánchez es el encargado de contar a Jaime los atropellos sufridos.

${ }^{76} \mathrm{Rg}, 1521 \mathrm{j} 28$ vto./4 7-XII-1308. Las cantidades especificadas sumadas a las que ya conocemos no alcanzan la cifra ya conocida. Suponemos que desconocemos alguna entrega, pues Jaime espocifica lo que se debe entregar para que Alfonso obtenga la famosa cantidad: 10.000 del portaggo de la puerta de Bisagra, 18.000 de la de Mostiniego de Madrid, 12.000 de la de Medina del Campo; en cambio, de las tercias que el día de Pascua Florida haya hecho entregar es cosa de los predicadores de Calatayud, CCXXXIIJ maravedises que se le deben. Además pide que se le presten al infante de la Cerda los homenajes que se le deben y se cumpla todo lo estipulado. 
Ignoramos si por el deseo general de llevar a feliz término tales reclamaciones y también por ser necesario solucionar los asuntos referentes a las relaciones de los reinos peninsulares entre sí, aprovechando un momento de sosiego y paz, los monarcas de Aragón y Castilla decidieron entrevistarse de nuevo en el Monasterio de Santa María de Huerta, el 1 de noviembre de 1308.

En dicha reunión se trataron múltiples asuntos: matrimonios entre infantes de ambos reinos, colaboración en la conquista de Almería..., quedando muy en segundo lugar la solución del pleito del infante Alfonso de la Cerda. Esta vez podemos asegurar que el rey de Aragón actuó de forma que, de haberse cumplido sus proyectos, la solución lograda hubiese sido muy eficaz. Se especificó todo lo que Fernando de Castilla debía entregar a su primo para que éste alcanzase a cobrar $400 \mathrm{mil}$ maravedises de renta"

Si estos extremos llegaron a cumplirse fue con gran demora, puesto que el 21 de enero del año siguiente, 1309, desde Poitiers, Alfonso volvió a pedir a Jaime que insistiese para que se le entregase lo estipulado ${ }^{78}$. Hubo una nueva reclamación el 20 de febrero ${ }^{79}$, pero todo quedaria igual, puesto que el 8 de junio Palazín, el ya conocido embajador aragonés, fue enviado al infante don Juan de parte de Jaime. No sabemos qué resultado dio tal embajada, pues lo que de ella resultó debía contarlo Palazín ${ }^{80}$. Más tarde, el 5 de diciembre del mismo año, Fernando reclamó al rey de Aragón la carta que éste le debía sobre el pleito de Alfonso de la Cerda. ${ }^{81}$. La respuesta fue rapidísima; dos días después el monarca aragonés le especificaba lo que se le debía dar al infante para que las rentas que se produjeran alcanzasen la cantidad estipulada de 400 mil maravedises ${ }^{82}$.

Lo único que hace dudar de que tales entregas se llevasen a cabo total o parcialmente es que el infante Fernando de la Cerda rogó a Jaime que obligase a su hermano a entregarle lo que le pertenecía según el ordenamiento conocido ${ }^{83}$.

77 RCD, caja $25 / 3159$.

78 CRD, caja $30 / 3736$.

79 CRD, caja 29/3650, 8-VI-1308.

${ }^{80}$ CRD, caja 29/3650, 8-VI-1308.

${ }^{81}$ CRD, caja 27/3416, 5-XII-1308.

${ }^{82} \mathrm{Rg} .1521 / 26$ vt. 1, 7-XII-1308. Como las anteriores donaciones no llegaban a dicha cantidad, habria que sumar 10.000 maravedises del poriazgo de la puerta de Bisagra, 18.000 de la martiniega de Madrid y 12,000 de la de Medina del Campo, como cambio de unas tercias que no se especifican. Además se le debían a Alfonso 233.000 maravedises no sabemos por qué concepto. La entrega de todo esto debía efectuarse como plazo máximo el día de Paseua en la casa de los predicadores de Calatayud. Se insistía también en que se le prestasen al infante los homenajes que se le debían.

${ }^{83}$ CRD 25/3159, 28-I-1309. 
Alfonso de la Cerda había encargado a Martín López de Peña Aguda que informase a Jaime del estado de $\cos ^{8}{ }^{84}$. El inquieto infante don Juan, en buena armonía con su sobrino y conservando la amistad del rey de Aragón, recibió a Guillén Palazín, embajador de este último, para tratar del caso de Alfonso de la Cerda ${ }^{85}$. Las noticias verbales transmitidas no nos permiten saber de qué se trató, pero seguramente el infante intentaría valorar ante el rey de Aragón, protector oficial del pretendiente, su ayuda a dicha causa.

Podemos presumir cuáles eran las relaciones de los infantes Alfonso y Fernando con los monarcas de Aragón y Castilla, interpretando algunas noticias que nos permiten suponer que las entregas no se llevaron a cabo, puesto que se encontraban en Almazán, desde donde rogaron a Jaime que respetase la tregua que el rey de Castilla había firmado con el infante don Juan. Su situación no debía ser muy halagüeña cuando claramente Femando le dijo a Jaime «que no le deje pasar el hambre que está pasando ${ }^{86}$. Podemos asegurar que Jaime respondió a la petición de auxilio, pero que las donaciones no tuvieron lugar como lo prueba la promesa de Jaime al infante Alfonso de que haría todo lo posible para que durante el transcurso del mes de agosto se le entregase lo que se le debía. No sabemos si era todo o sólo una parte de lo adjudicado ${ }^{87}$.

A partir de este momento, las noticias sobre los desdichados infantes cada vez aparecen más distanciadas, pero siempre ofrecen el mismo motivo, las entregas que Castilla no llevaba a cabo. Durante el año 1311 se sucedieron diversas reclamaciones, dándose el caso de que en febrero del citado año el concejo de Almazán prestó homenaje y juramento a la infanta Maria de Aragón en la persona de su representante Miguel Pérez de Arbe ${ }^{88}$. Fue entonces cuando se llevó a cabo el compromiso matrimonial entre la mencionada infanta y Pedro de Castilla, circunstancia que permite suponer que el rey Fernando consideraba dicha villa como propia. Recordemos que en circunstancias anteriores Alfonso lamentó haberla entregado.

Un año después, en febrero de 1312, Jaime volvió a ocuparse del asunto de la Cerda. En sus gestiones cerca de Fernando de Castilla, le dijo que su primo se quejaba de la demora que sufrían sus asuntos, pero a su vez Jaime dice que le ha reprendido a causa de su insistencia en llamarse rey y no dejar de usar las armas reales según los pactos establecidos y aceptados. Con la misma fecha, Jaime dio cuenta a los infantes don Juan y don Pedro de su carta a Fernando, rogando al primero que le tenga al corriente de la opinión de su sobrino sobre el asunto, al mismo tiempo que le indicaba que

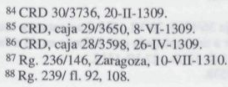


procurase el ánimo de Fernando hacia el cumplimiento de lo pactado, por considerar que era la mejor solución ${ }^{89}$. Nada se resolvio, puesto que unos días después se vuelve a hablar de Deza y Serón, asunto que Jaime no pudo poner en claro según le contó al infante Pedro, ya que Alfonso de la Cerda reclamaba lo que se le había adjudicado en las vistas de Sta. María de Huerta, más 60 mil maravedises. A pesar de todo, Jaime prometió a su futuro yerno que procuraría *cobrar los dichos lugares por a vos por la quarta parte de 230 mil maravedises ${ }^{90}$. Esta noticia parece demostrar que Jaime estaba dispuesto a favorecer al infante Pedro mermando los intereses del infante Alfonso. Jaime se disgustó al conocer las noticias que le dio su enviado fray Lorenzo de la orden de predicadores.

Le contrarió considerablemente enterarse de que Fernando «os ha tomado de lo vuestro e de como a don Johan vuestro fijo el qual enviavades al rey havian salteado o encalçadon. Algo de verdad tendrian las quejas que comentamos, cuando Fernando se sinceró cerca de Jaime de los cargos que se le hacían a causa de sus diferencias con su primo, a quien acusa de haber vendido unas tierras sin poder hacerlo".

Una nueva intervención del Pontífice se produjo de manera indirecta. Jaime notifica a Fernando que el Papa deseaba que el asunto de de la Cerda se resolviese, y que la única manera de conseguirlo era concediéndole tierras con mero y mixto imperio. Pero cuando dicha noticia llegó a Castilla ya Fernando había fallecido (9 de septiembre de 1312), según la reina viuda Constanza anunció al rey de Aragón ${ }^{92}$. Los últimos años de la vida del pretendiente a la corona de Castilla no ofrecen particular interés. Despojado de todo, marchó a Francia, desde donde regresó en 1331 prestando fidelidad a Alfonso XI.

Salvo en las primeras actas documentales, hemos prescindido de las siglas ACA correspondientes al Archivo de la Corona de Aragón, ya que todos los documentos utilizados proceden de dicho archivo. En las siglas CRD, Cartas reales diplomáticas, ocurre lo mismo, pues todas pertenecen al reinado de Jaime II de Aragón.

A causa del espacio concedido, cuya amplitud nos hemos visto obligados a rebasar, no figura un pequeño apéndide documental, que esperamos pueda ser suplido por los breves resúmenes incluidos en las notas.

${ }^{89} \mathrm{Rg}, 1521 \mathrm{fl}, 130 / \mathrm{v}$, y 131 . Teruel, 13-II-1312.

${ }^{90} \mathrm{Rg} .239$ fl. 219, $25-\mathrm{II}-1312$.

91 Rg. 239 fl. 248 vto,, 5-IV-1312. CRD, caja 36/4513, 20-VI-1312. Lamentamos mucho no poder ofrecer íntegro un documento referente a una embajada que Alfonso envio a Jaime debido a su mal estado de conservación. Rg, 1521 fl. 131/v., 27-VI-1312.

${ }^{92}$ Rg. 240 fl, 62, 24-VIII-1312 y CRD, $35 / 4538$. 


\section{BIBLIOGRAFIA}

BenaVides Navarrete, Antonio, Memorias del reinado de Fernando IV. Gaibrois de Ballesteros, Mercedes. María de Molina. Historía del reinado de Sancho IV.

GIMÉNEZ SOLER, Andrés. Don Juan Mamuel.

SoldeVIla, Ferran. Historia de Catalunya. Historia de España.

Zurrta, Jerónimo de. Anales de la Corona de Aragón, libro V. 